\title{
THE MECHANISM OF DOCUMENTING THE ARTS AND ITS ROLE IN PRESERVING HERITAGE USING MODERN TECHNIQUES "FIELD STUDY ON FOLKLORE MUSEUMS"
}

Walaa Muhammad Mahmoud AHMED *

Academy of Arts, Ministry of Culture, Egypt

\begin{abstract}
The research presented the target value of the art documentation mechanism, and its role in preserving the heritage using modern technologies, as the arts in general, and the visual arts in particular, have a significant role in the advancement of societies, and stand strictly about what and the mechanism for defining arts within societies, and the role of the arts In view of the technical development day after day, and afternoon after era, modern technologies have a role and importance that cannot be underestimated in the field of traditional arts in a great depth, and if we study folklore museums, we will find that they contain many and many aesthetic, artistic and plastic values that It deals with and expresses the aspects of social, cultural and civilizational change within societies, and we also found that every environment is subject to a set of factors that shaped its human and intellectual manifestations of a culture. This is what attributed us to the importance of documenting all this, going back to the foundations, as well as the scientific methodology that makes us preserve our heritage by using the latest technologies of what our ancestors left us in depth, thinking, and building our present, and then we advance our future by joining forces, private and public institutions to form a shield Protective against external intellectual invasion, the next enemy is the enemy of ideas, the attacker of civilizations, and science, and in order for the documentation mechanism to be optimized, all technical, technical and thematic aspects must be taken into account to include the important issues in heritage museums in specialized electronic archives by creating databases and electronic websites With the use of collecting modern information, in image and sound, to display every information in its place for easy transmission and retrieval when needed; In addition to making documentary films and showing them on heritage preservation sites, which necessitates establishing a group of sites concerned with heritage preservation on several levels.

Keywords

Heritage, Folk Museums, Documentation Mechanism, The Most Important Modern Technologies.
\end{abstract}

\section{Introduction}

Documentation is the basic tool that we do to preserve the heritage, and enhance its content for reference when needed. Therefore, we must protect it and prove the credibility of its source. Documentation takes a set of definitions, including: It is the process of accurate, comprehensive and comprehensive preservation of information, which aims to preserve the cultural production If we expose the information rich heritage, we will find that the documentation includes a set of mechanisms that help it cover all the heritage topics in a clear, and useful way after a comprehensive and comprehensive technical development in various modern technologies, which must be used to cover the various topics of folk museums. It has a great, firm and stable value, expressing all our heritage topics in many forms.

The word (authentication) was derived from the word document, and any wisdom documented the subject to be documented. The use of the term documentation has prevailed until it has

*Corresponding author: media@moc.gov.eg 
become a common term for those concerned in all fields of information and culture to a large extent, and it is used today in the field of heritage preservation in a more robust and tight way. With information magnification, it has come to mean collecting, organizing, storing, analyzing and transmitting information to the beneficiaries. Folklore museums are considered one of the most important cultural institutions interested in preserving and protecting information and heritage sources that document the human, social, political, and religious history of peoples, and they may vary. Folklore museums differ from one cultural environment to another and from one region to another, so each society has its own characteristics, and according to features. Of societies show the mechanism by which heritage is preserved.

\section{Research Problem:}

The necessity to establish a special mechanism for preserving and documenting heritage, especially folklore museums, by using the latest technologies, not to be exposed to the most important institutions concerned with folklore, especially museums, and to talk about them, and to be exposed to their methods.

\section{The Goals of Research:}

Definition of the documentation process and its mechanism, exposure to the most important modern techniques of documentation - monitoring the most important folklore museums, their types, and the most important heritage elements in them.

\section{Research Methodology:}

The research follows the descriptive-analytical approach, which is concerned with monitoring, describing, and analyzing the elements of the topic and the ethnographic approach.

First: Defining the documentation process and its mechanisms:

It is one of the types of art that aims to preserve information and transfer it from one place to another with the aim of returning to it when needed. There are many different types of documentation such as books, books, manuscripts, newspapers, magazines, audio documentation, photographs, and videos.

The features that distinguish the document as a material for preservation are as follows:

- Objectivity and impartiality: as it is objectively edited by the official body that produces it, and in this capacity it is considered an integral part of the activity of the institution that produced or received it, so nothing is expected of it except the truth as it is part of the work of the administration that produced it.

- Credibility: It means that it contains correct information free of doubt because it was subject to the will of the official authority that produced it, or whoever represents it legally or legally, in contrast to the information contained in novel sources such as 
books and periodicals, as it is willingly subject to error and correctness.

- Natural: where the documents are formed naturally through the practice of the official body for its continuous daily work and activities.

- Interrelationships: as each document has close relations with the rest of the other documents, whether they are inside or outside the documentary group, so it is difficult - in many cases - to understand the contents of a document without referring to the other documents that are related to it, so when organizing it improves The arrangement of documents according to the principle of origin or origin.

To make a document well, the following must be done:

1- Defining its objectives, the current nature of its work, and the future goals it intends to achieve.

2- Defining and defining the activities and activities that the concerned party exercises and which it requires to achieve current and future goals.

3- Establish working contexts for each process or activity that the concerned party exercises within its competence and the nature of its work.

4- Developing forms to facilitate the implementation of, and application of, work contexts.

5- Preparing an internal control system to verify that the quality management system is properly implemented.

In order to set a work context for each activity or process, the following steps must be followed:

1- Establishing a Documents Controlling System

2- Determine the purpose of the activity or process.

3- Defining the objectives of the process.

4- Determining the persons entrusted with the implementation of the event, with a description of the responsibility of each one.

5- Define the process details.

6- Defining the special forms for applying the process.

7- Determining the timing of the review, updating the context of the work of the process as a whole, and calculating the observations generated by the application.

8- Determine the method of preserving documents, correspondence, maps, photos, and videos of the process and where they are saved.

\section{The Importance of Documenting More Specifically:}

Documentation is an integral part of the process of preserving heritage in all its aspects, especially since the largest part of the heritage is the arts. The graphic arts and the visual arts 
both need to be preserved. If we divide the subjects of the arts, we find that they are divided into:

- Saying arts: They are the arts that combine proverbs, riddles, myths, poetry, and all literature in its various forms and types, each of which has its own nature.

- Visual arts: they are the arts that are exposed to folk crafts, traditional works of art, material culture, and plastic arts of all kinds. From wall drawings, etc., as well as performing arts from folk music groups, folklore, and folk dance groups. Each of the two previous arts has a method of preservation and presentation. There are traditional methods, and there are more modern methods. The traditional methods used to be summarized in the use of paper and pen. The more modern methods are the methods that use photographic cameras, video cameras, and audio recorders. Day after day there is a great development in the use of such methods due to the rapid technical development that It happens day after day on a higher scale, and in many different and distinct forms.

The graphic arts use paper and pen to preserve its materials, but the visual arts need greater depth and more comprehensive, and more sophisticated techniques and tools. Like cameras, the use of cameras varies according to the subject of the arts to be recorded, as kinetic or performing arts need video cameras, while static arts such as buildings and heritage facilities can use fixed cameras, and audio recorders are important in both cases.

\section{Documentation Stages:}

First stage: In this stage, we sort the sources from books, newspapers, pamphlets, and publications.

The second stage: after sorting the sources of information according to specialization and interest, and according to the program of the information center and archive.

The third stage: It is the stage of identifying or testing the topic from the sources that are actually sorted, and this stage is not related, like others, to a specific dialect or organization, but rather at the initiative of those who are assigned to do so.

The fourth stage: It is a subsequent stage to the third, and is complementary to it, and it defines the organizational direction of the selected and selected information.

Second: Exposure to the most important modern technologies through which we can document: Therefore, we must study the digital creation of the image, display its content, and how to display that content through a special mechanism.

\section{Digital Creativity of Photo:}

When talking about the influential role of digital creativity of the image and its use in highlighting the topics of the popular heritage, it was necessary to address the most important 
elements and mechanisms that helped, and help to highlight the popular heritage in a new way, without change or distortion, whether by addition or deletion. We bear a very difficult responsibility for very specific topics related to the cultures of the expressed peoples, and therefore the use of digital creativity had some caveats that must be taken into account when choosing topics and expressing them. Because we have a duty to document the popular heritage in all its manifestations, and therefore we look at the concept of digital creativity of the image. Creativity is faith in everything that is new and beautiful, through the employment of different, different, and higher capabilities, whether the expression is through any type of science or arts, such as language, music, plastic arts, photography, or documentary films. This creativity or conversations are directed to the hearing, the sight, or both, and in the non-linguistic arts, creativity turns into ideas through the language in which we think without leaving us from within. As for literature that addresses the senses and the feeling beautifully, and the mind with its ideas. That is, literature addresses the level of feeling and emotion with the mind, and thus it was the most common one in building knowledge. The image inside the modern means of communication is extremely quick to reach the recipient, with all the contents of the picture, the contents of science and literature, and "advertising" and "media" loaded with information. This requires it, "and the arts should stop to recognize the data and the effect of the image. We are in this time in the process of highlighting the role of the popular heritage, by which today the progress of nations is measured. A bright past is what produces a happy present, and what creates a developed future. Using digital creative technical means that serve each topic in its field.

\section{The Digital Creation of the Image Has Some Aspects, Namely:}

First - Facilitating the communication of artists with each other, to exchange views and experience, and facilitate the establishment of joint exhibitions, or even the establishment of virtual exhibitions. It is true that digital painting and its programs simulate traditional and realistic art, whether in results, or even in the work environment, but since the advent of digital technology, electronic drawing programs have greatly influenced the traditional and realistic drawing. Digital programs have facilitated the learning of art, while here we rely on history museums due to the nature of the material, and these museums specialize in displaying human history and human achievements in the fields of politics, industry, agriculture and other things. The history in which museums specialize, as it is difficult for a single museum of history to be familiar with all branches, and for all times, as the folklore is displayed, and the popular legacies are represented in everything that fathers and grandfathers left for us in terms of heritage, whether represented in its intellectual or material side. Linguistically with the term 
heritage. But the difference lies in the fact that the heritage still performs its functional role today, in contrast to the popular legacies that are supposed to have lost their functional role. Museums play an important role in the lives of peoples, as they are not a storehouse for artifacts, but have transformed over time into places for the manufacture of culture and the consolidation of identity, but crafts museums in the Islamic world are still few, and although their role is unclear, one of the most important tasks of museums is to preserve cultural heritage Which is an important element in the establishment of the unity of any people with a diversity of cultural heritage, as the material that may be used in many different paths of research is preserved, hence the paramount importance of museums in the field of crafts, as it can document the skills of making art pieces, and the sequence of the process Industry, which was produced according to specific environmental, cultural, economic and geographical conditions, therefore it is considered a record of the uncodified culture of the peoples.

A group of heritage museums in the Arab Republic of Egypt:

\section{Results :}

1- Modern technologies have more than one major role in documenting arts, and each of the techniques has a special mission.

2- The fictional arts has a documentary mechanism that is somewhat different from the performing or kinetic arts, and each type has a method

Private documentary.

3- Folklore museums contain many aspects of cultural, social and human life that must be preserved.

\section{Recommendations:}

1- Taking care of our artistic and cultural heritage through museum visits, and documenting everything that is in it.

2- The presence of specialists and researchers within the institutions concerned with heritage preservation who have the ability to create programs

Developmental heritage preservation.

3- Conducting training workshops and seminars whose main task is to train on the latest documentation techniques to benefit from all that is new in the field of documentation.

\section{References:}

1- Hasan Ahmad Issa: Creativity in Art and Science, Scientist 18: Knowledge, Kuwait, December 19, p: 18

2- Alaa Muhammad Mahmoud Hassaballah: Folk traditions and their influence on sculpture in the New Valley Governorate (study 
Field), Master's Thesis, Department of Folk Art and Material Culture, Higher Institute for Folk Art, Academy of Arts, 2015.

3- Nessma Al-Batriq: Significance in Cinema and Television in the Age of Globalization, Dar Gharib, Cairo, 2004

4- The Nubia Museum: State Information Service, Wednesday, 12:00 a.m. - September 30, 2008.

$5-$

http://www.sis.gov.eg/Story/1726/\%D9\%85\%D8\%AA\%D8\%AD\%D9\%81\%D8\%A7\%D9\%84\%D9\%86\%D9\% 88\% D8\% A8\% D8\% A9? Lang = en

6- Virtual Digital Museum: https://virtualalorifan.blogspot.com/p/normal-0-false-false-falseen-us-X-none.html

7- Ahmed Muhammad Muhanna AL-NUGHAITHER, STUDY OF METHODS AND TECHNIQUES OF IMPLEMENTING ROCK DRAWINGS OF NEWLY DISCOVERED ROCK DRAWINGS IN SEVERAL ARCHAEOLOGICAL SITES IN NAJD REGION KINGDOM OF SAUDI ARABIA, International Journal of Multidisciplinary Studies in Heritage Research, Vol. 2, No. 2, 2019, pp. 18-23.

Received: February 11, 2020

Accepted: April 9, 2020 